\title{
PENGARUH TERAPI BERMAIN PUZZLE TERHADAP PERKEMBANGAN MOTORIK HALUS PADA ANAK PRA SEKOLAH DI TK INTI GUGUS TULIP III PADANG TAHUN 2018
}

\author{
Yuanita Ananda ${ }^{1}$ \\ ${ }^{1}$ Pasca Sarjana Keperawatan Unand \\ Email: Yuanita_ananda88@yahoo.com
}

\begin{abstract}
Yuniati's research (2018) in TK At Taqwa Mekarsari Cimahi showed that 17 puzzle intervention groups found that most of the children before being given puzzle type educational games, medium fine motoric $(64.7 \%)$, the rest were $(35.3 \%)$ respondents have low fine motor development. The purpose of the study was to determine the effect of puzzle play therapy on fine motor development in pre-school children in Inti Tulip III Padang Kindergarten in 2018. This type of research is pre-experiment with one group pretestposttest approach. The sample in this study were 15 children. The sampling technique used total sampling .. Data collection by observation on August 25, 2018. Data were analyzed by univariate and bivariate using paired samples T-test statistical test. The results of the study mean fine motor development before being given therapy to play puzzles in kindergarten Tulip III Core Group Padang mean 7.87 standard deviation 1.246. The mean fine motor development after being given therapy to play puzzles in kindergarten. Inti Tulip III Padang Group with a mean value of 9.93 standard deviation of 1.534. There is an effect of the child's fine motor development before and after therapy is playing puzzle in kindergarten Tulip Group III Padang in 2018 with p-value (0,000).. The conclusion of the research about playing puzzle therapy can affect fine motor skills in children. It is suggested that playing puzzle therapy can be applied at the kindergarten Tulip Group III. And it is hoped that this research can be developed with other therapies to see the fine motor development of pre-school children.
\end{abstract}

Keywors: Puzzle Play Therapy and Fine Motor Development

\section{ABSTRAK}

Penelitian Yuniati (2018) di TK At Taqwa Mekarsari Cimahi didapatkan hasil bahwa 17 orang kelompok intervensi puzzle, didapatkan bahwa sebagian besar anak sebelum diberikan permainan edukatif jenis puzzle, motorik halusnya sedang yaitu $(64,7 \%)$, selebihnya adalah $(35,3 \%)$ responden memiliki perkembangan motorik halus rendah. Tujuan penelitian untuk mengetahui pengaruh terapi bermain puzzle terhadap perkembangan motorik halus pada anak pra sekolah di TK Inti Gugus Tulip III Padang Tahun 2018. Jenis penelitian ini pre eksperimen dengan pendekatan one group pretest-posttest. Sampel pada penelitian ini adalah 15 anak. Teknik pengambilan sampel menggunakan total sampling.. Pengumpulan data dengan cara observasi pada tanggal 25 Agustus 2018. Data dianalisa secara univariat dan bivariat menggunakan uji statistik paired samples T-test. Hasil penelitian rerata perkembangan motorik halus sebelum diberikan terapi bermain puzzle di TK Inti Gugus Tulip III Padang dengan nilai mean 7,87 standar deviasi 1,246. Rerata perkembangan motorik halus sesudah diberikan terapi bermain puzzle di TK Inti Gugus Tulip III Padang dengan nilai mean 9,93 standar deviasi 1,534. Terdapat pengaruh perkembangan motorik halus anak sebelum dan sesudah dilakukan terapi bermain puzzle di TK.Inti Gugus Tulip III Padang tahun 2018 dengan p-value $(0,000)$. Kesimpulan penelitian terapi bermain puzzle dapat mempengaruhi kemampuan motorik halus pada anak. Diharapkan terapi bermain puzzle dapat diterapkan di TK Inti Gugus Tulip III. Dan diharapkan penelitian ini dapat dikembangkan dengan terapi lain untuk melihat perkembangan motorik halus anak pra sekolah.

\section{Kata Kunci : Terapi Bermain Puzzle dan Perkembangan Motorik Halus}




\section{PENDAHULUAN}

Anak prasekolah adalah anak yang berusia antara 3-6 tahun. Dalam usia ini anak umumnya mengikuti program anak (3 tahun- 5tahun) dan kelompok bermain (Usia 3 Tahun), sedangkan pada usia 4-6 tahun biasanya mereka mengikuti program Taman Kanak-Kanak (Patmonedowo, 2008)

Proses utama perkembangan anak merupakan hal yang saling berkaitan antara proses biologis, proses sosioemosional dan proses kognitif. Ketiga hal tersebut akan saling berpengaruh satu sama lain dan sepanjang perjalanan hidup manusia. Selama proses perkembangan tidak tertutup kemungkinan anak menghadapi berbagai masalah yang akan menghambat proses perkembangan selanjutnya. Perkembangan tersebut mencakup perkembangan prilaku sosial, bahasa, kognitif, fisik/motorik (Depkes, 2012)

Kemampuan motorik halus yang baik, agar menentukan seseorang untuk melakukan aktivitas yang baik pula, misalnya menyisir rambut, memasang tali sepatu, mengancingkan baju, menulis dan lain-lain. Hal ini akan menunjang aktivitas dalam kehidupan dalam seharihari terutama untuk diri sendiri perkembangan motorik tidak semuanya dapat berjalan mulus, karena dipengaruhi oleh banyak faktor. Salah satu faktor lingkungan, struktur fisik, kematangan, kesempatan, belajar dan berlatih (Fitri, 2012).

Kemampuan motorik dapat dikembangkan melalui aktivitas bermain yang berhubungan dengan keterampilan fisik yang melibatkan otot kecil serta koordinasi antara mata dan tangan, seperti bermain puzzle, maze, menyusun balok, memasukkan benda ke dalam lubang sesuai bentuknya, membuat garis, melipat kertas, dan menulis dengan huruf sesuai dengan bentuknya (Decaprio, 2013).

Puzzle merupakan sejenis permainan yang berupa potonganpotongan gambar yang cara bermain nya yaitu dengan menyusunnya sehingga terbentuk sebuah gambar, dengan tujuan untuk melatih kesabaran, memudahkan peserta didik dalam memahami konsep, memecahkan masalah, saling bekerja sama dengan teman, serta mengembangkan keterampilan motorik dan kognitif murid. (Herawati, 2013)

Hasil penelitian yang dilakukan oleh Lilis (2018) tentang Metode Bermain Puzzle Berpengaruh Pada Perkembangan Motorik Halus Anak Usia Pra Sekolah yang dilakukan di Lamongan sebagian besar perkembangan anak usia prasekolah sebelum diberikan metode bermain puzzle adalah normal sebanyak 26 anak (59\%) dari 44 orang anak. Setelah diberikan metode bermain puzzle adanya peningkatan perkembangan motorik halus yaitu sebanyak 38 orang anak.

Hasil Penelitian yang dilakukan oleh Erni Yuniati (2018) tentang Puzzle Mempengaruhi Perkembangan Motorik Halus Anak Usia Pra Sekolah di TK At Taqwa Mekarsari Cimahi didapatkan hasil bahwa 17 orang kelompok intervensi puzzle, didapatkan bahwa sebagian besar anak sebelum diberikan permainan edukatif jenis puzzle, motorik halusnya sedang yaitu $(64,7 \%)$, selebihnya adalah $(35,3 \%)$ responden memiliki perkembangan motorik halus 
rendah. Setelah dilakukan intervensi permainan edukatif jenis puzzle sebagian besar anak motorik halusnya dalam kriteria tinggi yaitu $(64,7 \%)$, anak dengan perkembangan motorik halus sangat tinggi yaitu $(23,5 \%)$ dan selebihnya $(11,8 \%)$ responden memiliki motorik halus sedang.

Berdasarkan data dari Dinas Pendidikan Kota Padang tahun 2018 terdapat 305 sekolah TK, setelah peneliti melakukan observasi pada dua sekolah TK yang berada di wilayah padang, dari hasil wawancara kepala sekolah dan wali kelas TK Bhayangkari mengatakan sudah diterapkan permainan puzzle untuk perkembangan motorik halus pada anak, dan pada TK Bhayangkari mempunyai tema yang diterapkan tiap hari nya, sedangkan permainan puzzle di TK Inti Gugus Tulip III yang terletak di Jl. Bunda Raya No.1 Ulak Karang, Kec. Padang Utara hanya sesekali menerapkan permainan tersebut, karena di TK Inti Gugus Tulip III ini dalam perkembangan motorik memakai kartu bergambar, menyusun balok, dan tidak ada menerapkan tema seperti TK Bhayangkari.

Setelah dilakukan survei awal peneliti di TK Inti Gugus Tulip III di kelas TK B jumlah murid di TK tersebut sebanyak 20 orang. Dari hasil observasi terdapat 5 orang anak yang bermasalah terhadap perkembangan motorik halus, terlihat dari si anak masih kurang mampu menggambar, dan mewarnai dengan rapi karena masih kaku dalam memegang pensil maupun crayon.

Berdasarkan fenomena dan fakta diatas, maka peneliti tertarik untuk melakukan penelitian dengan judul "Pengaruh Terapi Bermain Puzzle Terhadap Perkembangan Motorik Halus Pada Anak PraSekolah Di TK Inti Gugus Tulip III Kota Padang 2018”.

\section{METODE PENELITIAN}

Penelitian ini telah dilaksanakan di TK Inti Gugus Tulip III. Jenis penelitian yang pre eksperiment dengan pendekatan one group pretest-posttest. Populasi adalah keseluruhan dari objek penelitian atau objek yang diteliti. Populasi pada penelitian ini adalah seluruh murid TK kelas B sebanyak 15 orang dengan teknik pengambilan yaitu total sampling. Teknik pengumpulan data yang dipergunakan dalam penelitian ini yaitu pengumpulan data primer dengan melakukan lembar observasi keterampilan motorik halus sebelum dan sesudah dilakukan terapi bermain. Penelitian ini menggunakan analisis Univariat dengan distribusi rerata motorik halus sebelum dan sesudah dilakukan terapi bemain dan analisis Bivariat dengan menggunakan uji statistik $t$-test paired samples $(<0,05)$.

\section{HASIL DAN PEMBAHASAN Analisa Univariat}

Tabel 1.1

Rerata Perkembangan Motorik Halus Sebelum diberikan Terapi Bermain Puzzle di TK. Inti Gugus Tulip III Padang Tahun 2018

\begin{tabular}{lccc}
\hline $\begin{array}{l}\text { Perkembangan } \\
\text { Motorik Halus }\end{array}$ & n & Mean & $\begin{array}{c}\text { Standar } \\
\text { Deviasi }\end{array}$ \\
\hline Sebelum & 15 & 7,87 & 1,246 \\
\hline
\end{tabular}

Berdasarkan tabel 1.1 dapat dilihat bahwa rerata perkembangan motorik halus sebelum diberikan terapi bermain puzzle di TK. Inti Gugus Tulip III Padang dengan nilai mean 7,87 standar deviasi 1,246.

Hasil penelitian ini hampir sama dengan penelitian Maghfuroh (2018) tentang pengaruh penggunaan alat permainan metode bermain puzzle berpengaruh pada perkembangan motorik halus anak usia prasekolah di TK. Surya Baru Desa 
Plosowahyu Lamongan ditemukan hasil sebelum diberikan terapi bermain dengan mean 59\%. Ada pengaruh penggunaan alat permainan metode bermain dengan perkembangan motorik halus anak dengan $p$ value $=0,001$. Selain itu penelitian ini sejalan Yuniati (2018) Puzzle Mempengaruhi Perkembangan Motorik Halus Anak Usia Prasekolah di TK At Taqwa Mekarsari Cimahi ditemukan hasil mean sebelum 3,35. Ada pengaruh permainan puzzle dengan perkembangan motorik halus pada anak dengan $\mathrm{p}$ value $=$ 0,0001 .

Menurut Susanto (2011) motorik halus adalah gerakan yang melibatkan gerakan-gerakan yang lebih halus dilakukan oleh otot-otot baik. Gerakan halus ini memerlukan koordinasi yang cermat. Semakin baik gerakan motorik halus sehingga membuat anak dapat berkreasi. Magil dalam (Sumantri, 2005) keterampilan motorik halus ini melibatkan koordinasi neuromuscular (syaraf otot) yang memerlukan ketetapan derajat tinggi untuk berhasilnya keterampilan ini. Keterampilan ini sering disebut sebagai keterampilan yang memerlukan mata dan tangan (hand-eyes coordination).

Menurut analisa peneliti bahwa perkembangan motorik halus pada anak di TK. Inti Gugus Tulip III sebelum diberikan terapi bermain puzzle dengan rata-rata 7,87. Rendahnya kemampuan motorik halus pada anak ini dikarenakan faktor lingkungan serta kepribadian anak juga dapat mempengaruhi keterlambatan dalam perkembangan motorik. Anak yang sering dimanja oleh orang tuanya sering mengalami keterlambatan pekembangan motorik halus. Dimana orang tua sering melarang anak menggunakan gunting, bermain dengan benda keras sehingga perkembangan motorik halus anak terlambat.

Tabel 1.2

\section{Rerata Perkembangan Motorik Halus Sesudah diberikan Terapi Bermain Puzzle di TK. Inti Gugus Tulip III Padang Tahun 2018}

\begin{tabular}{lccc}
\hline $\begin{array}{l}\text { Perkembangan } \\
\text { Motorik Halus }\end{array}$ & n & Mean & $\begin{array}{c}\text { Standar } \\
\text { Deviasi }\end{array}$ \\
\hline Sesudah & 15 & 9,93 & 1,534 \\
\hline
\end{tabular}

Berdasarkan tabel 1.2 dapat dilihat bahwa rerata perkembangan motorik halus sesudah diberikan terapi bermain puzzle di TK. Inti Gugus Tulip III Padang dengan nilai mean 9,93 standar deviasi 1,534.

Hasil penelitian ini hampir sama dengan penelitian Maghfuroh (2018) tentang pengaruh penggunaan alat permainan metode bermain puzzle berpengaruh pada perkembangan motorik halus anak usia prasekolah di TK. Surya Baru Desa Plosowahyu Lamongan ditemukan hasil sebelum diberikan terapi bermain dengan mean $88,4 \%$. Ada pengaruh penggunaan alat permainan metode bermain dengan perkembangan motorik halus anak dengan $p$ value $=0,001$. Selain itu penelitian ini sejalan Selain itu penelitian ini sejalan Yuniati (2018) Puzzle Mempengaruhi Perkembangan Motorik Halus Anak Usia Prasekolah di TK At Taqwa Mekarsari Cimahi ditemukan hasil mean sesudah 1,88. Ada pengaruh permainan puzzle dengan perkembangan motorik halus pada anak dengan $\mathrm{p}$ value $=0,0001$.

Metode Bermain Puzzle berpengaruh pada Perkembangan Motorik Halus Anak Usia Prasekolah, sebab bermain puzzle dapat mengkoordinasi gerak mata dan tangan anak, dengan itu tanpa mereka sadari motorik halus mereka terus terlatih dan berkembang dengan bagus. Selain itu, ketika mereka bermain puzzle anak dapat berlatih untuk mengenal bentuk dan bagaimana mereka mengisi ruang kosong dimana potongan-potongan tersebut di perlukan. 
Puzzle juga mendorong anak untuk mengenali persamaan, seperti bagaimana warna yang merah atau garis tebal di dalam suatu potongan sesuai dengan corak yang sama pada potongan yang lain. Melalui permainan ini anak-anak dapat belajar bahwa suatu benda atau objek tersusun dari bagian-bagian kecil. Permainan ini mendorong anak mengerti cara mengkombinasikan unsur-unsur yang berbeda.(Andriana, 2011).

Menurut analisa peneliti bahwa terdapat perkembangan motorik halus pada anak di TK. Inti Gugus Tulip III sesudah diberikan terapi bermain puzzle dengan ratarata 9,93. Bermain puzzle merupakan media bermain sederhana yang dimainkan secara bongkar pasang yang membutuhkan ketelitian, karena anak dilatih untuk dapat memusatkan pikiran agar dapat berkonsentrasi, selain itu dengan bermain puzzle anak belajar tentang konsep bentuk, warna, ukuran dan jumlah yang dapat membantu mengembangkan kemampuan motorik halus anak dengan melibatkan koordinasi mata dan tangan serta melatih otot-otot jari tangan.

Tabel 1.3

\section{Rerata Pengaruh Perkembangan}

Motorik Halus Anak Sebelum dan

Sesudah dilakukan Terapi Bermain Puzzle

di TK. Inti Gugus Tulip III

Padang Tahun 2018

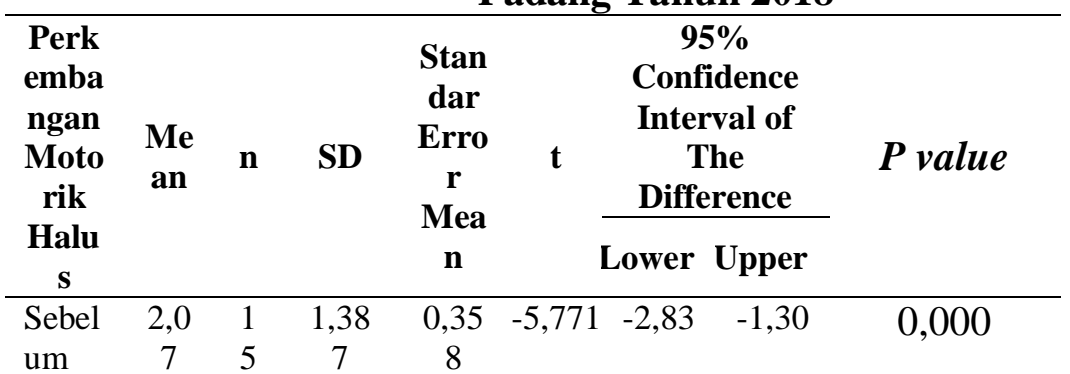

dan

Sesu

dah bermain puzzle adalah mean 2,07. Setelah dilakukan uji statistik paired samples T-test didapatkan nilai $p$ value $(0,000) \alpha<0,05$. Maka terdapat pengaruh perkembangan motorik halus anak sebelum dan sesudah dilakukan terapi bermain puzzle di TK. Inti Gugus Tulip III Padang tahun 2018.

Hasil penelitian ini hampir sama dengan penelitian Maghfuroh (2018) ditemukan hasil ada perbedaan sebelum dan sesudah diberikan terapi bermain puzzle ditemukan selisih mean 4,6. Setelah dilakukan uji statistik paired samples $T$-test didapatkan nilai $p$ value $(0,002)<\alpha 0,05$. Maka terdapat pengaruh penggunaan alat permainan metode bermain puzzle berpengaruh pada perkembangan motorik halus anak usia prasekolah ditemukan hasil sebelum diberikan terapi bermain puzzle.

Selain itu penelitian ini sejalan Yuniati (2018) Puzzle Mempengaruhi Perkembangan Motorik Halus Anak Usia Prasekolah di TK At Taqwa Mekarsari Cimahi ditemukan hasil ada pengaruh pemberian terapi puzzle terhadap perkembangan motorik halus anak usia pra sekolah $(p$ value $=0,001)$.

Kemampuan motorik dapat dikembangkan melalui aktivitas bermain yang berhubungan dengan keterampilan fisik yang melibatkan otot kecil serta koordinasi antara mata dan tangan, seperti bermain puzzle (Decaprio, 2013). Puzzle merupakan sejenis permainan yang berupa potongan-potongan gambar yang cara bermainnya yaitu dengan menyusunnya sehingga terbentuk sebuah gambar, dengan tujuan untuk melatih kesabaran, memudahkan peserta didik dalam memahami konsep, memecahkan masalah, saling bekerja sama dengan teman, serta mengembangkan keterampilan motorik dan kognitif murid (Herawati, 2013)

Analisa peneliti perbedaan sebelum dan sesudah perlakuan terapi bermain puzzle ini ditemukan perbedaan peningkatan terapi selisih rerata perkembangan motorik halus sebelum dan sesudah dilakukan terapi 
bermain puzzle dengan selisih 2,07. Hal ini dikarenakan setelah dilakukan perlakuan selama 25 menit pada masing-masing anak ditemukan perubahan. Sebelum dilakukan perlakuan sebanyak 3 orang rendah, 11 orang tinggi dan 1 orang sangat tinggi dalam puzzle. Setelah dilakukan perlakuan didapatkan hasil sebanyak 1 anak masih rendah, 5 orang anak tinggi dan 9 anak kemampuan motorik sangat tinggi. Bermain puzzle dapat meningkatkan keterampilan motorik halus merupakan kemampuan yang berhubungan dengan otot-otot kecil, terutama tangan dan jari-jari tangan dan melatih koordinasi mata dan tangan. Melalui aktivitas bermain puzzle, tanpa disadari anak akan belajar secara aktif untuk menggunakan jari-jari tangannya untuk menyusun gambar yang tepat.

\section{SIMPULAN}

Rerata perkembangan motorik halus sebelum diberikan terapi bermain puzzle di TK. Inti Gugus Tulip III Padang dengan nilai mean 7,87 standar deviasi 1,246. Rerata perkembangan motorik halus sesudah diberikan terapi bermain puzzle di TK. Inti Gugus Tulip III Padang dengan nilai mean 9,93 standar deviasi 1,534. Terdapat pengaruh perkembangan motorik halus anak sebelum dan sesudah dilakukan terapi bermain puzzle di TK. Inti Gugus Tulip III Padang tahun 2018.

\section{UCAPAN TERIMA KASIH}

Dalam menyelesaikan penelitian ini, peneliti telah mendapatkan bimbingan, masukan dan bantuan dari berbagai pihak sehingga pada kesempatan ini peneliti mengucapkan terima kasih kepada : Kepala Tk Inti Gugus Tulip III yang telah memberikan izin untuk pengambilan data penelitian, anak prasekolah yang telah bersedia menjadi responden dalam proses penelitan,
Semoga segala bantuan yang telah diberikan menjadi amal sholeh dan mendapat balasan dari Allah SWT. Peneliti menyadari bahwa penelitian ini masih banyak kekurangan dan kelemahannya. Kritik dan saran akan sangat berarti agar tumbuh dan terbentuknya sebuah pemikiran yang baru untuk kesempurnaan penelitian ini, peneliti akan menerimanya dengan rasa terima kasih yang tak terhingga.

\section{DAFTAR PUSTAKA}

Adriana. 2011. Tumbuh Kembang dan Terapi Bermain Pada Anak. Jakarta: Salemba Medika

Decaprio, 2013. Aplikasi Pembelajaran Motorik di Sekolah. Jogjakarta: Diva Press

Depkes RI. 2006. Pedoman Pelaksanaan Stimulasi Deteksi dan Intervensi Dini Tumbuh Kembang Anak ditingkat Pelayanan Kesehatan Dasar.

Desmita. 2009. Psikologi Perkembangan Peserta Didik. Bandung : PT Remaja Rosdakarya

Yuniati. E, 2018. Puzzle Mempengaruhi Perkembangan Motorik Halus Anak Usia Pra Sekolah di TK At Taqwa Mekarsari Cimahi.11 (1)

Fitri. 2012. Meningkatkan Motorik Halus Dalam Memegang Alat Tulis Melalui Teknik Mencongkel Bagi Anak Autis.1 (2)

Herawati. 2013. Pembelajaran Kooperatif TAI dan game puzzle dalam meningkatkan motivasi belajar dan pemahaman konsep.

Junaidi. 2011. Kehamilan Sehat Dan Mengatur Jenis Kelamin Anak. Yogyakarta: C.V ANDI OFFESET

Maghfuroh, 2018. Metode Bermain Puzzle Berpengaruh pada Perkembangan Motorik Halus Anak Usia Prasekolah di TK. Surya Baru Desa Plosowahyu Lamongan, Jurnal Skripsi 
Nabiel. 2014. Buku Ajar Keperawatan Anak.

Yogyakarta : Pustaka Pelajar

Nidho. 2013. Upaya Meningkatkan Pengenalan Geometri Dengan Permainan Puzzle Bervariasi Pada Kelompok B TK AL-HIKMAH Randudongkal-Pemalang

Febriana. 2015. Pengaruh Penggunaan Alat Permainan Edukatif Maze Alur Tulis Terhadap Keterampilan Motorik Halus Pada Anak Kelompok A TK ABA Janturan Umbulharho Yogyakarta

Notoatmodjo. 2012. Metodologi Penelitian Kesehatan, Jakarta : Rineka Cipta

Patmonodewo. 2008. Pendidikan Anak Pra Sekolah. Jakarta : Rineka Cipta

Sumantri. 2005. Pengembangan Keterampilan Motorik Anak Usia Dini. Jakarta: Dinas Pendidikan

Susanto, 2011. Perkembangan Anak Usia Dini Pengantar dalam Berbagai Aspeknya. Jakarta : Kencana Perdana Media Group

Wong. 2009. Buku Ajar Keperawatan Pediatrik. Jakarta : EGC

Yuniarni. 2010. Metode Pengembangan Anak Usia Dini : Pontianak 